\title{
The Decomposition of Dichloropropionate by Soil Micro-organisms
}

\author{
By A. N. MACGREGOR* \\ Department of Microbiology, Uni:ersity of Otago, Dunedin, New Zealand
}

(Received 4. July 1962)

\begin{abstract}
SUMMARY
When a column of air-dried soil was perfused with a mineral salt solution containing 'Dalapon' (Dow Chemical Company, Michigan), the concentration of dichloropropionate (Dalapon's herbicidal component) became minimal in 15-17 days. The soil was reperfused and the dichloropropionate became minimal in 4-5 days.

Three strains of the genus Pseudomonas, exhibiting a requirement for dichloropropionate, were isolated from the perfusate. Two strains attacked dichloropropionate when allowed to perfuse through sterilized soil.

A further seven micro-organisms, with a similar requirement, were isolated from pasture soils treated with Dalapon.
\end{abstract}

\section{INTRODUCTION}

Audus (1951), Walker (1954), Theigs (1955) and Jensen (1957) showed that many of the indigenous micro-organisms of soils could break down herbicides. In the absence of leaching, Theigs (1955) attributed the disappearance of Dalapon in the soil to the action of Dalapon-decomposing organisms, as the rate of decomposition was greater in soils of higher bacterial numbers than in infertile soils. He found similarities to the pattern of 2,4-dichlorophenoxyacetic acid (2,4-D) disappearance observed by Audus (1951).

Jensen (1957) isolated micro-organisms of the genus Agrobacterium from soil and found them able to attack Dalapon. Magee \& Colmer (1959) isolated eight micro-organisms able to decompose Dalapon, six tentatively classified as species of Agrobacterium and two of Pseudomonas. Hirsch \& Alexander (1960) isolated a number of bacteria and species of Streptomyces, Nocardia, Penicillium and Aspergillus that could attack Dalapon. The present investigation seeks further evidence for the degradation of dichloropropionate in the soil by micro-organisms.

\section{METHODS}

Soil. Soil for perfusion was taken from three adjacent plots of pastureland, each 2 sq.yd. in area; they had never been treated with Dalapon and had been under grass for several years. Soil from one plot was sampled and removed to the laboratory. The two remaining plots were sprayed with aqueous solutions of Dalapon for 8 consecutive months from summer to early spring, one at $10 \mathrm{lb}$./acre, the other at 5. Both treated plots were sampled at the end of the 8-month period.

\footnotetext{
* Present address: Tasman Vaccine Laboratory Ltd., Upper Hutt, New Zealand.
} 
In sampling the soil, adjacent 6 in.-deep sods were dug and the top 1 in. of turf removed. After air-drying at room temperature between layers of newsprint, the 1.0-4.0 mm. crumb fraction was collected by sieving.

Perfusion fluid and apparatus. The perfusion fluid was as follows: $\mathrm{MgSO}_{4} \cdot 7 \mathrm{H}_{2} \mathrm{O}$ 1.0 g., $\mathrm{CaCl}_{2} 1.0$ g., $\mathrm{NaCl} 1.0$ g., $\mathrm{K}_{2} \mathrm{HPO}_{4} 5.0$ g., $\left(\mathrm{NH}_{4}\right)_{2} \mathrm{SO}_{4} 5.0$ g., $\mathrm{FeCl}_{3} .6 \mathrm{H}_{2} \mathrm{O}$ $10.0 \mathrm{mg}$., distilled water to $1 \mathrm{l}$. It was adjusted to $\mathrm{pH} 6.8$ and when prepared in bulk steamed for $2 \mathrm{hr}$. daily for 3 days.

The perfusion apparatus was similar to that used by Audus (1946).

Dichloropropionate. The source of crude dichloropropionate was Dalapon (W. R. Mullison, private communication) and added so that the final concentration in the perfusion fluid was $\mathbf{0 . 2} \%$. Pure sodium 2,2-dichloropropionate was prepared as described by Macgregor (1960).

Dichloropropionate was assayed colorimetrically. Samples were assayed for pyruvate (Friedman \& Haugen, 1943) following autoclaving for $40 \mathrm{~min}$. at $120^{\circ}$.

\section{Soil perfusion}

Untreated soil. Soil crumbs from the untreated plot were perfused with the salt solution containing an estimated $2 \mathrm{mg}$. dichloropropionate $/ \mathrm{ml}$., until no dichloropropionate could be detected. The soil perfusate was then drained off, the freshly perfused soil left intact and the reservoir replenished with fresh perfusion fluid plus dichloropropionate. Perfusion was recommenced and continued until the dichloropropionate became minimal. (Sterilized soil crumbs were perfused with and without dichloropropionate addition.)

Auxotrophic micro-organisms requiring dichloropropionate were isolated by streaking a loopful of the soil perfusate on to solid medium. This was a $2 \%$ washedagar gel of the perfusion fluid with sterile dichloropropionate rubbed into the gel before inoculation. After incubation for 5 days at $28^{\circ}$, colonies were picked off and inoculated into tubes of the perfusion fluid containing dichloropropionate to $0.5 \%$, $\mathrm{w} / \mathrm{v}$. The tubes were examined for growth after similar incubation.

Inoculated soil. Sterilized soil crumbs were brought to maximal moisture-holding capacity with dichloropropionate-perfusion fluid and inoculated with a visibly turbid suspension of each strain isolated as above. Perfusion was continued for 4 days. After this perfusion, all strains were re-isolated in pure culture.

Treated soil. Soil crumbs from the plots of land sprayed at 5 and $10 \mathrm{lb}$./acre respectively with Dalapon, were perfused and micro-organisms with a dichloropropionate requirement isolated.

\section{RESULTS}

Untreated soil. By plotting the concentration of dichloropropionate in the perfusate of the first-perfused soil against time, two phases of disappearance of dichloropropionate were noted: (i) a lag phase lasting 9-10 days; (ii) active dichloropropionate removal lasting a further 6-7 days. These occurred in all perfusion experiments, although the time for each phase varied with the soil (unperfused, reperfused or inoculated soil).

Reperfusion of the initially unperfused soil resulted in more efficient removal of dichloropropionate. The lag phase was decreased to 1-2 days with complete removal 


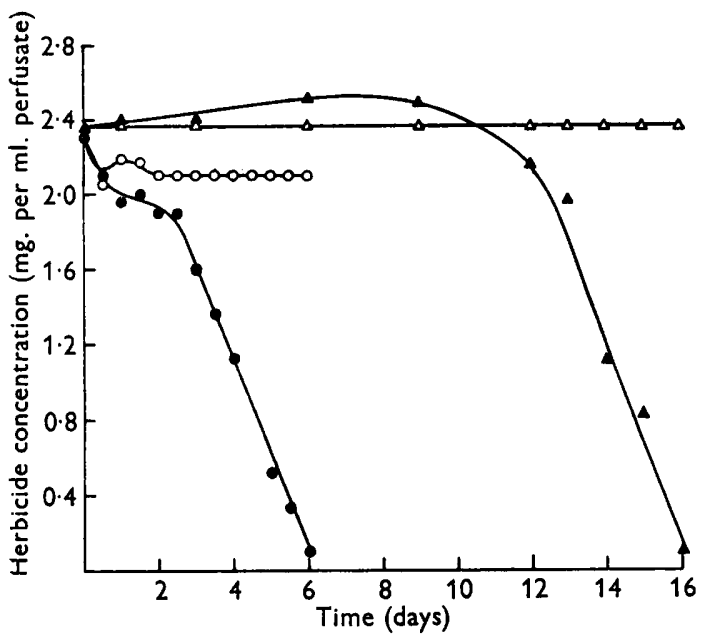

Fig. 1

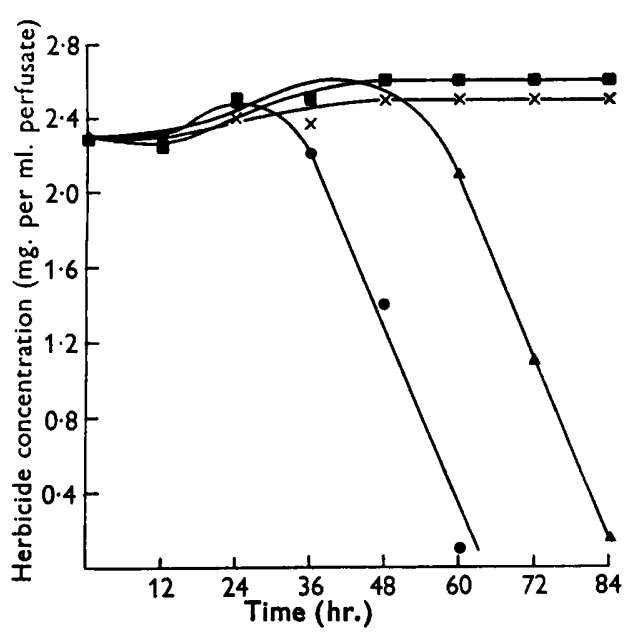

Fig. 2

Fig. 1. Untreated soil. The disappearance of dichloropropionate from various perfused soils. $\Delta-\Delta$, Unperfused soil + dichloropropionate; -0 , reperfused soil + dichloropropionate; $\Delta-\Delta, \bigcirc-O$, sterilized soil + dichloropropionate.

Fig. 2. Inoculated soil. The disappearance of dichloropropionate from the perfusates of sterilized soil inoculated with micro-organisms with a requirement for dichloropropionate. $\Delta-\Delta$, Soil inoculated with isolate $A$; $-\bullet$, soil inoculated with isolate $B ; \square-\square$, soil inoculated with isolate $C ; x-x$, uninoculated soil.

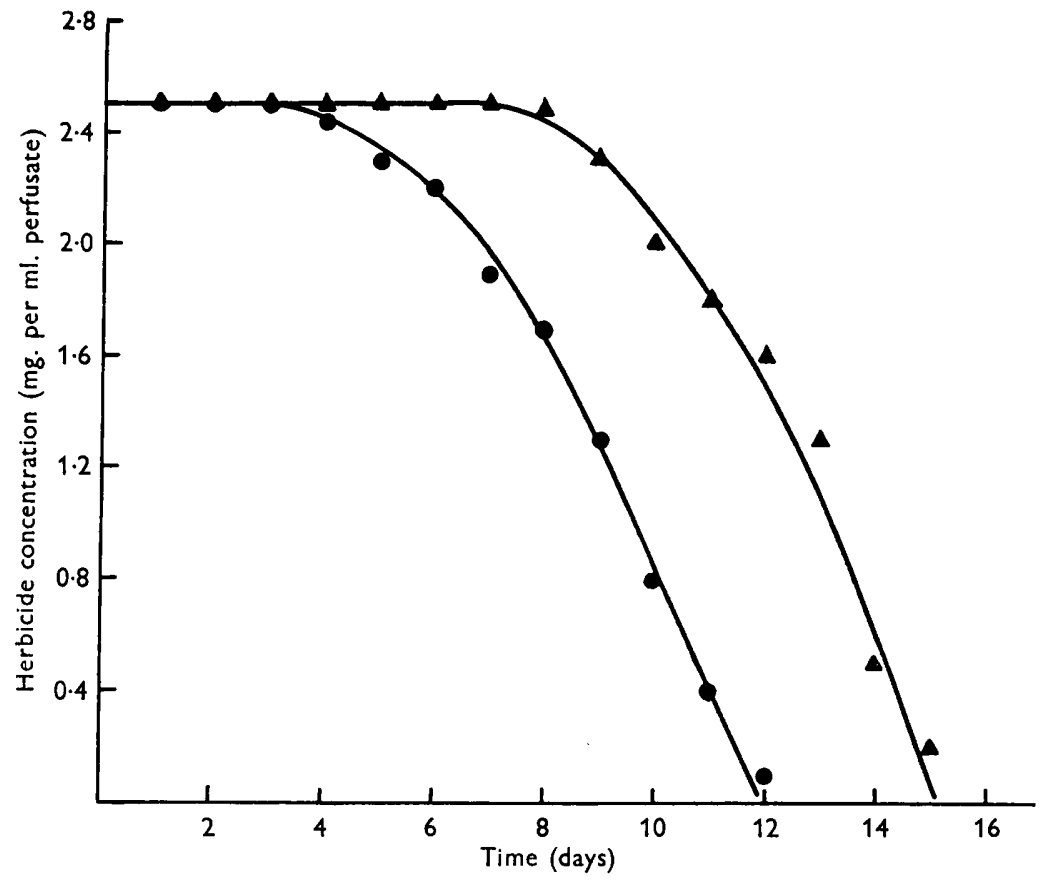

Fig. 3. Treated soil. The disappearance of dichloropropionate from the perfusates of treated soils. $\Delta-\Delta$, Soil dosed at $5 \mathrm{lb}$./acre of Dalapon; $-\bullet$, soil dosed at $10 \mathrm{lb}$./ acre of Dalapon. 
after a further 4-5 days (Fig. 1). In both the perfusion of unperfused and reperfused soil, sterilizing the soil failed to minimize dichloropropionate.

Inoculated soil. The disappearance of dichloropropionate from the inoculated soils followed the trend of disappearance from the reperfused soil. However, after 4. days, dichloropropionate disappeared in only two soils (Fig. 2).

Three micro-organisms exhibiting a requirement for dichloropropionate were isolated. They were Gram-negative motile rods with single polar flagella and measured $1 \cdot 5-1 \cdot 0 \times 0.5 \mu$. They were unable to grow anaerobically and showed growth at 30-35 ${ }^{\circ}$. A zone of blue-green fluorescence occurred around the growth on Difco nutrient agar. All three isolates hydrolysed gelatine, produced an alkaline reaction in litmus milk but with no clot formation, and produced nitrite from nitrate. They did not digest cellulose or produce indole. Although growth occurred in glucose-, lactose- and maltose-peptone media, no acid or gas was produced after 4 days incubation. Slight variations in colony morphology occurred on Difco nutrient agar and dichloropropionate agar. These characteristics suggest that the strains may be closely related members of the genus Pseudomonas (Bergey's Manual 1957).

Treated soil. The pasture soils treated with Dalapon were sampled 20 days after the last spraying. No residual dichloropropionate was detected and it was therefore anticipated that dichloropropionate added to the fluid perfusing these would be removed in less than 20 days. No dichloropropionate was detected in either soil perfusate after 16 days perfusion (Fig. 3).

Seven micro-organisms were isolated from treated soils and shown to have a requirement for dichloropropionate. Five were Gram-negative rods and two branched in young cultures, and formed a pellicle in Difco nutrient broth.

\section{DISCUSSION}

The kinetics of the disappearance of dichloropropionate from the untreated soil perfusate are consistent with the hypothesis that a soil enrichment causes some segment of the microbial population to proliferate. It then adapts to the conditions imposed by the enrichment material (Audus, 1951). The graphs illustrating the removal of dichloropropionate from the various perfusates reflect the growth of suitably adapted micro-organisms.

Ten micro-organisms have been isolated during the course of the investigation that require dichloropropionate for growth, perhaps as a sole source of carbon. These micro-organisms present an interesting facet of bacterial metabolism in view of the structural similarity of dichloropropionate to other halogenated fatty acids, e.g. trichloroacetate, iodoacetate and fluoroacetate. The site of dehalogenation of the dichloropropionate molecule has recently been investigated by Hirsch \& Alexander (1960).

I wish to acknowledge the help given by Mr F. A. Meeklah in conducting field trials. Thanks are due to $\mathrm{Mr}$ E. Facer for constructing the perfusion units. 


\section{REFERENCES}

Audus, L. J. (1946). A new soil perfusion apparatus. Nature, Lond. 158, 419.

Audus, L. J. (1951). The biological detoxification of hormone herbicides in the soil. Plant \& Soil, 3, 170.

Bergey's Manual of Determinative Bacteriology (1957). 7th ed. Ed. by R. S. Breed, E. G. D. Murray \& N. R. Smith. London: Baillière, Tindall \& Cox Ltd.

Friedman, T. E. \& Haugen, G. E. (1943). The determination of keto-acids in blood and urine. J. biol. Chem. 147, 415.

Hirsch, P. \& Alexander, M. (1960). Microbial decomposition of halogenated propionic and acetic acids. Canad. J. Microbiol. 6, 241.

JENSEN, H. L. (1957). Decomposition of chlorosubstituted aliphatic acids by soil bacteria. Canad. J. Microbiol. 3, 151.

Macgregor, A. N. (1960). The biological detoxification of Dalapon in the soil and its effect on some micro-organisms. M.Sc. thesis, University of Otago, New Zealand.

MAgee, L. A. \& Colmer, A. R. (1959). Decomposition of 2, 2-dichloroproprionic acid by soil bacteria. Canad. J. Microbiol, 5, 261.

Theigs, B. J. (1955). The stability of Dalapon in soils. Down to Earth, 11. Trade journal of Dow Chem. Co. Midland, Mich., U.S.A.

Walker, N. (1954). Preliminary observations on the decomposition of chlorophenols in soil. Plant \& Soil, 5, 194. 